\title{
CHARACTERISATION OF BREAKING WAVES ON THE EDDYSTONE LIGHTHOUSE: A LABORATORY INVESTIGATION ON WAVE PRESSURE
}

\begin{abstract}
D. Banfi ${ }^{1}$, A. Raby ${ }^{1}$ and D. Simmonds ${ }^{1}$
Commonly, rock lighthouses are erected on the top of steep reefs and in limited water depths. The effect of these environmental conditions on wave loading requires deeper understanding. This paper investigates wave loading at small scale for a particular case study: the Eddystone lighthouse (UK). Load characteristics due to breaking waves are obtained by the use of pressure transducers and the test program is designed to generate a comprehensive data set covering a broader range of wave conditions. Although the magnitude of wave pressures is rather random from wave to wave of the same train of regular waves, the pressure impulsivity tends to decrease with increasing relative breaking distance. Four breaker types are described and particular attention is given to time histories of the line of action of horizontal force and vertical spatial distributions. Estimation of overall forces, obtained by pressure integration, indicates that the wave loading is strongly affected by the limited water depth condition. In fact, only small plunging waves are able to break at the structure; thus, they cause small forces despite the small breaking distances. Finally, the occurrence of the breakers is investigated on a dimensionless plane given by the combination of the Iribarren number and momentum flux of Hughes.
\end{abstract}

Keywords: Eddystone lighthouse; limited water depth; breaking waves; wave load; spatial load distributions; breaking map

\section{INTRODUCTION}

Wave loads are usually categorised as non-breaking or breaking waves. While wave loading due to non-breaking waves is well understood, the wave-structure interaction due to breaking waves further adds to the difficulty in predicting the underlying processes. This is essentially given by the intrinsic random nature of wave pressure due to the unknown mixture of water-air involved during the breaking process (Bullock et al. 2001). So far, multiple laboratory tests have been carried out in order to investigate the effects of breaking waves on load characteristics i.e. load peak, impact duration and spatial distribution. While many of these investigations have been focused on vertical or near vertical walls (Oumeraci et al. 1993; Hattori et al. 1994; Hull and Muller 2002; Bullock et al. 2007), very few studies have been conducted on structures as rock lighthouses (Kyte and Tørum 1996). Commonly, rock lighthouses are erected on the top of steep reefs and in limited water depths. Relatively little is known about the effects of these environmental conditions on wave loading. The objective of the present paper is to investigate, at small scale, the load characteristics due to breaking wave for a particular case of study: the Eddystone lighthouse (UK). Geophones and cameras were installed on this structure, which is located on a perilous group of rocks some $21 \mathrm{~km}$ offshore from Plymouth. The field monitoring showed that the lighthouse can be exposed to different types of breaking waves (Raby et al. 2015).

\section{LITERATURE REVIEW \\ Breaking waves and load characteristics}

Bagnold (1939) was one of the first to perceive that wave loading is affected by the amount of aeration involved during the breaking process. Thus, the coastal literature has provided several breaker classifications on the basis of the breaking shape/breaking distance (Oumeraci et al. 1993; Hattori et al. 1994; Hull and Muller 2002) or the amount of air measured under controlled conditions (Bullock et al. 2007). Although it is not possible to identify the breaker that causes the highest pressure, severe loads are usually associated with plunging impacts that break at the structure, i.e. characterised by small breaking distances or low aeration levels. In addition, it is generally accepted that the impulsivity tends to decrease with the increase in the breaking distance and the aeration effect results in a cushioning effect (visible with a pressure oscillation), which tends to damp the pressure peak and to increase the impact duration (Oumeraci et al. 1993; Hattori et al. 1994; Hull and Muller 2002; Bredmose et al. 2009; Cuomo et al. 2011). Typically, broken waves exhibit much smaller pressures than plunging impacts. However, the latest considerations concerning the highest load peaks were not found for High Mound Composite Breakwaters (HMCBs), which are characterised by large and steep mounds that cause a limited water depth at the toe of the vertical superstructure. As a consequence, only small waves

\footnotetext{
${ }^{1}$ Faculty of Marine and Science Engineering, Plymouth University, Drake Circus, Plymouth, Devon, PL4 8AA, UK
} 
are able to break at the superstructure, thereby causing lower loads despite the small breaking distance (Muttray et al. 1998).

For design purposes, a full characterisation of wave loads requires the identification of spatial distributions in order to determine the line of action of the force. Especially for rock lighthouses, which can have a tapered geometrical configuration, the spatial distribution can play a fundamental role in terms of structural deflections. In particular, for the Eddystone lighthouse, numerical simulations have been carried out with a view to analyse the structural response of the tower. The investigation indicates that the structural deflection of the Eddystone lighthouse is highly influenced by the height at which the impacts occur. In particular, maximum displacements show a steep linear trend with impact height (Trinh et al. 2016). Concerning vertical walls, distinct pictures have been given in the literature about the location of maximum pressure since the spatial distribution tend to be random for breaking waves, even for regular waves that were supposedly identical. Large scale experiments of Bullock et al. (2007) show a sharp triangular distribution of maximum peaks (non-instantaneous) slightly above the still water level (SWL) for low aeration level. For high aeration levels, the triangular distribution tends both to enlarge and to centralise more close to the SWL; while broken impacts result in smoother and extended distributions with extreme pressures around or just below the SWL (Bullock et al. 2007).

\section{Laboratory tests and wave parameters}

Most of the aforementioned breaker classifications were obtained in 2D situations and with trains of regular waves. Small-scale tests introduce laboratory effects that are difficult to quantify (Bullock et al. 2003; Cuomo et al. 2010; Blenkinsopp and Chaplin 2011; Bredmose et al. 2015). However, one of the advantages of laboratory tests is the control over wave characteristics so as to understand the influence of various wave parameters on the wave loading during the process of breaking. Usually, the hydraulic variables (wave height $H$, wave period $T$ and water depth $h$ ) are combined to form dimensionless wave parameters, which helps to reduce the number of independent variables. Two of the most used coastal parameters are the Iribarren number and the momentum flux of Hughes (2005).

\section{Iribarren number}

The Iribarren number, also known as the surf similarity parameter (Battjes 1974), has been identified as a good predictor parameter in several design applications. It was initially developed to describe the occurrence of regular wave breaking on slopes as follows:

$$
\xi_{o}=\frac{\tan \alpha}{\sqrt{H_{o} / L_{o}}}
$$

where $\alpha$ is the slope of the seabed, $H_{o}$ the offshore wave height and $L_{o}$ is the offshore wave length, which is equal to $g T^{2} / 2 \pi$ (where $g$ is the gravity acceleration). Therefore, the Iribarren number relates the offshore wave steepness $H_{o} / L_{o}$ to the slope. This parameter is an index of the breaker violence through the well-known classification proposed by Galvin (1968), in which four categories of breaker are defined (spilling, plunging, collapsing and surging).

\section{Momentum flux of Hughes}

Hughes (2005) suggests that the Iribarren number may be not the best parameter to describe flow kinematics because local water depth $h$ is not included. Thus, while different combinations of $H / h$ (relative wave height) and $h / L$ (relative water depth) can yield the same value of deepwater wave steepness, the wave kinematics will be different. Consequently, Hughes (2005) considers the following dimensionless momentum flux (based on wave linear theory of Airy) as a better parameter to analyse wave-structure interactions:

$$
M_{\mathrm{f}}=\frac{1}{2} \frac{H}{h} \frac{\tanh k h}{k h}+\frac{1}{8}\left(\frac{H}{h}\right)^{2}\left[1+\frac{2 k h}{\sinh 2 k h}\right]
$$

where $k=2 \pi / L$ is the wave number and $L$ is the local wave length, which can be determined with the linear dispersion relationship (Eq. A-1 in Appendix). Eq. 2 indicates that $M_{\mathrm{f}}$ increases with the increasing of $H$ and/or $T$ and with the decreasing of $h$. 


\section{EXPERIMENTAL SETUP}

Regular wave tests were carried out in the $35 \mathrm{~m}$ long x $0.6 \mathrm{~m}$ wide $\mathrm{x} 1.2 \mathrm{~m}$ deep sediment wave flume of the COAST Laboratory at Plymouth University. The experiments were conducted at 1:70 length scale (Froude scaling) compared to the prototype and the bathymetry was modelled with two slopes: 1:20 and 1:8, as shown in Fig. 1. The water depths at the paddle and at the toe of the lighthouse model were $h_{p}=0.63 \mathrm{~m}$ and $h_{t}=0.095 \mathrm{~m}$, respectively, in agreement with the depths in the prototype at highest astronomical tide (i.e. $44 \mathrm{~m}$ and $6.65 \mathrm{~m}$ ).

The lighthouse model, which was screwed down to an uppermost horizontal plane located at the end of the 1:20 slope (Fig. 1), comprised two circular cylinders (one above the other) having different diameters. The cylindrical base had a height of $0.10 \mathrm{~m}$ and a diameter of $0.20 \mathrm{~m}$, the upper cylinder a height of $0.55 \mathrm{~m}$ and a diameter of $0.155 \mathrm{~m}$. The lighthouse model could be disassembled into two rigid parts, as shown in Fig. 2a, so that pressure transducers could be installed in nine $10 \mathrm{~mm}$ diameter threaded holes. The two parts were connected using eight screws and a perfect watertight was ensured by locating absorbing paper and petroleum jelly between them. The thickness of the cylinder walls was $10 \mathrm{~mm}$ and they were manufactured in Plexiglas in order to be simultaneously waterproof and rigid.

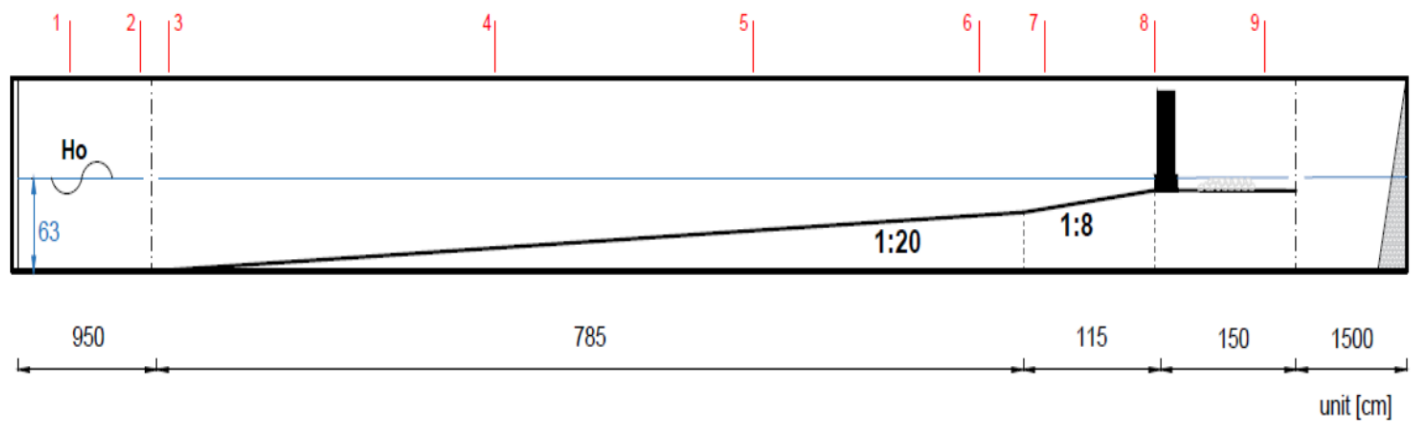

Figure 1. Setup of the experiments

Three of the threaded holes were under the SWL (on the cylindrical base) and six were above the SWL (on the upper cylinder); in order to provide the most detailed spatial resolution, two consecutive holes were spaced at intervals of $15 \mathrm{~mm}$ (Fig. 2b). Pressure signals were measured by six dynamic piezoelectric pressure sensors of type XP1102, which had a range of up to 1 bar and a resonant frequency of $50 \mathrm{kHz}$. Data was acquired at a sampling rate of $1.8 \mathrm{kHz}$. The six transducers were fixed as illustrated in Fig. 2b. Pressure transducer cables were inserted through another hole of $40 \mathrm{~mm}$ diameter on the leeside of the upper section model.

Finally, nine resistance wave gauges and three cameras completed the setup of the experiments. One of the three cameras was both high speed and high definition (3600 fps at 1024x1024 resolution).
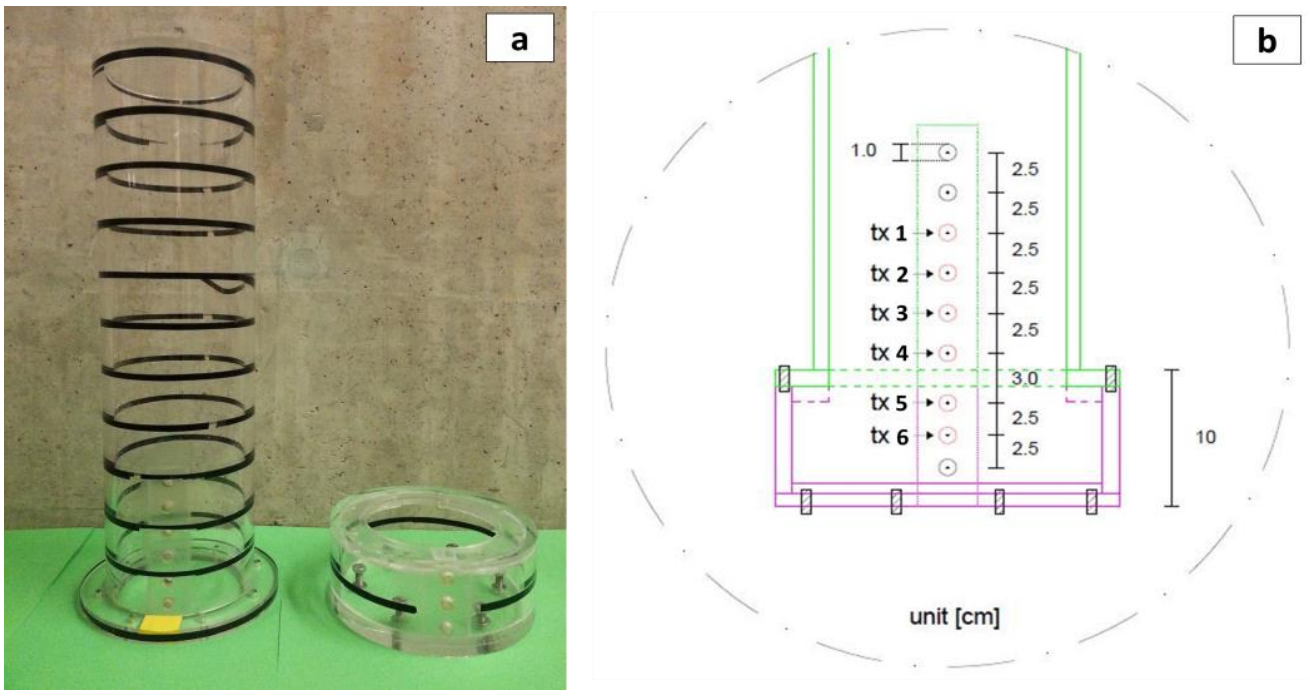

Figure 2. (a) Photo of the dissembled lighthouse model; (b) sketch of the pressure transducers locations 


\section{TEST PROGRAM AND THEORETICAL CONSIDERATIONS}

Experimental tests included 128 runs of regular waves (with target values of $H_{o}$ and $T$ covering 0.02-0.25 $\mathrm{m}$ and 0.6-3.0 s, respectively). These ranges of target values were identified thanks to a sort of breaking map, which was obtained in a dimensionless plane of momentum flux of Hughes versus Iribarren number and the, as shown in Fig. 3. On the horizontal axis, the Iribarren number (Eq. 1) was determined according to the uppermost slope $(\alpha=1 / 8=0.125)$ and the offshore wave steepness $\left(H_{\delta} / L_{o}\right)$. On the vertical axis, the momentum flux was determined according to Eq. 2 and setting $H=H_{o}$. As may be observed from Fig. 3, the test program is enclosed by three limiting conditions: the two breaking limits for wave steepness $(H / L)$ and wave height $(H / h)$, and the shallow water limit $(h / L)$. For determining the three limits, it was firstly necessary to identify the section at which the momentum flux is calculated, i.e. the value of the water depth $h$ that must be inserted into Eq. 2. It was decided to select the depth section at a distance from the model of approximately 5 times the maximum offshore wave height $\left(H_{o}=0.25 \mathrm{~m}\right)$; above this value the wave tends to dissipate most of the energy (Goda 1974). Thereby, the location was identified at a distance of $1.2 \mathrm{~m}$ from the model, where the water depth is $h^{*}=0.24 \mathrm{~m}$ and the slope is 1:20 (Fig. 1). As a consequence, the three limiting conditions were identified at $h^{*}$ according to the linear wave theory (Airy). Below are described the procedures used for their identification.

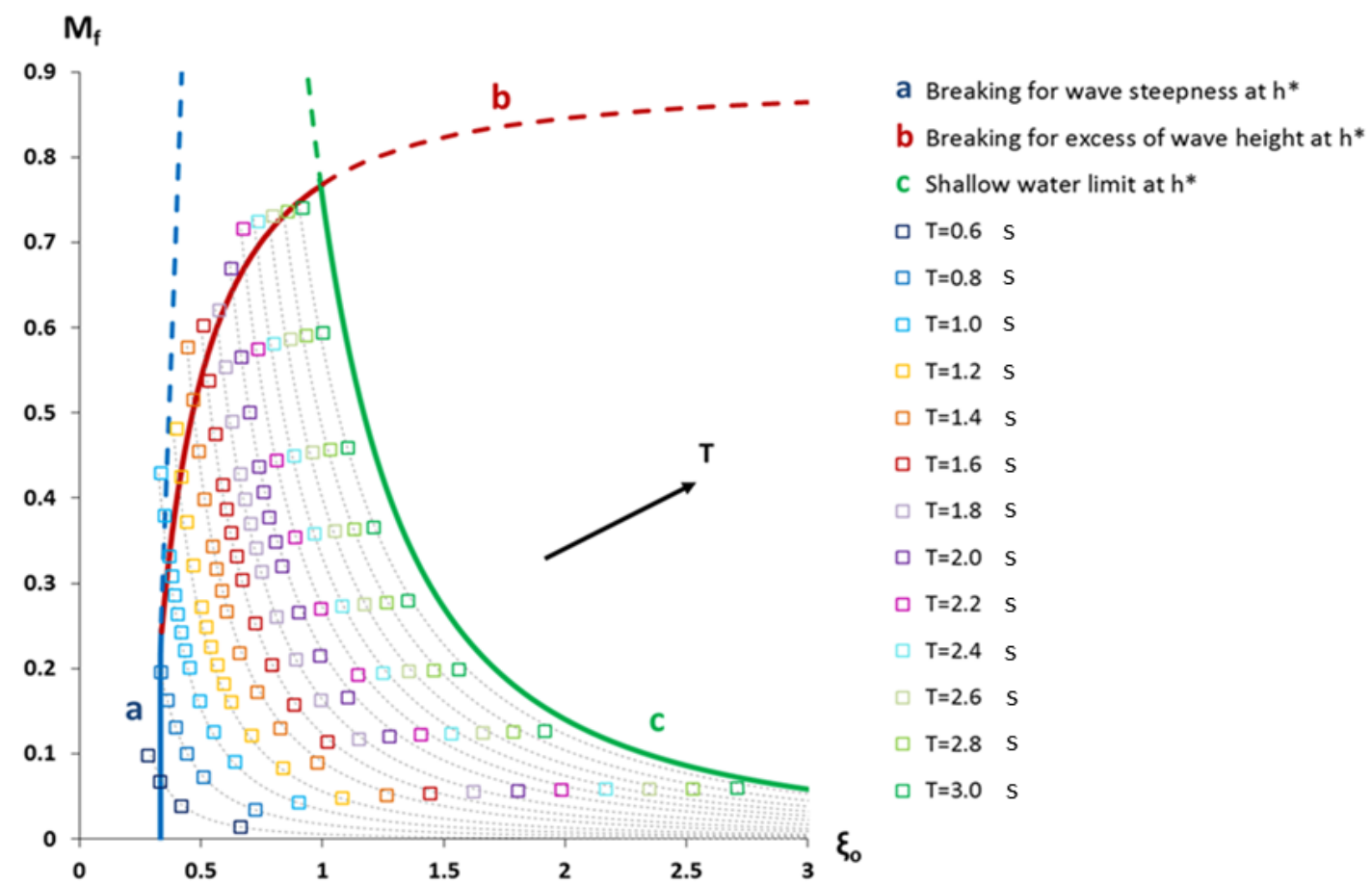

Figure 3. Test program plotted on the breaking map given by the combination of $\xi_{0}$ and $M_{f}$

\section{Breaking limit according to wave steepness}

The wave steepness limit $(H / L=0.14)$ was estimated by setting the breaking water depth $h_{b}$ at $h^{*}=0.24 \mathrm{~m}$ (note: subscripts "b" indicate wave characteristics at breaking point). A reduction coefficient of 0.91 was introduced to take into account the maximum possible decrease of the offshore wave height $H_{o}$ for shoaling (Fig. A-1 in Appendix). On this basis, the limit was determined as follows.

1. Define the wave steepness limit at $h_{b}$ equal to $0.91 H_{o} / L_{b}=0.14$

2. Select a value for $T$, e.g. $T=0.1 \mathrm{~s}$.

3. Calculate $L_{o}$ and $L_{b}$ at $h_{b}$ using the linear dispersion relationship (Eq. A-1 in Appendix).

4. Determine $H_{o}$ from step 1 above.

5. Repeat steps $2-4$ by defining different values of $T$ (with an interval $\Delta T=0.1 \mathrm{~s}$ ). 
Finally, the blue curve (a), shown in Figure 3, was drawn according to $\xi_{0}=\mathrm{f}\left(H_{o}, L_{o}\right)$ and $M_{\mathrm{f}}=\mathrm{f}\left(H_{o}\right.$, $T$ and $\left.h^{*}\right)$.

\section{Breaking limit according to wave height}

The breaking wave height $H_{b}$, on the 1:20 slope at $h_{b}=h^{*}=0.24 \mathrm{~m}$, was estimated as follows.

1. Define the breaking relationship between $H_{b} / h_{b}$ and $H_{b} / g T^{2}$ according to the Eq. A-2 (in Appendix) obtained from the diagram of Weggel (1972) (Fig. A-2 in Appendix).

2. Select the first value of relative wave height, $H_{b} / h_{b}=0.01$, with its relative value of $H_{b} / g T^{2}$ (from step 1).

3. Since $h_{b}=0.24 \mathrm{~m}$, define $H_{b}$ and, then, the associated $T$ (from step 2).

4. Determine both $L_{o}$ and $L_{b}$ at $h_{b}$ using the linear dispersion relationship (Eq. A-1).

Once these local variables were determined at the breaking location, it was necessary to calculate their relative offshore values, as explained below.

5. Known $h / L$ (i.e. $h_{b} / L_{\mathrm{b}}$ from step 4), identify the ratio $H_{(h)} / H_{o}$ from the shoaling curve (Fig. A-1).

6. Determine the value of $H_{o}$ from step 5, where $H_{(h)} \equiv H_{b}$.

7. Repeat steps $2-6$ by varying the values of $H_{b} / h_{b}$ (with an interval $\Delta=0.01$ ).

Finally, the red curve (b), shown in Fig. 3, was drawn according to $\xi_{0}=\mathrm{f}\left(H_{o}, L_{o}\right)$ and $M_{\mathrm{f}}=\mathrm{f}\left(H_{o}, T\right.$ and $\left.h^{*}\right)$.

\section{Shallow water limit}

The wave period $T$, which implies the shallow water limit at $h^{*}=0.24 \mathrm{~m}$, was calculated according to $h^{*} / L_{\left(h^{*}\right)}=0.05$, where the wavelength $L_{\left(h^{*}\right)}$ was determined using Eq. A-1.

Therefore, the blue limit (c), shown in Fig. 3, represents the curve at constant period ( $T=3.2 \mathrm{~s})$ that causes the shallow water limit at $h^{*}=0.24 \mathrm{~m}$.

\section{DATA PROCESSING}

\section{Vertical spatial distribution and time history of the line of action of the force}

Vertical spatial distributions have been determined applying a linear interpolation between the measured pressures. As shown in Fig. 4a, the spatial distribution was vertically extrapolated below the lowest transducer to the bottom and it was not extrapolated above the upper sensor. The spatial distribution was truncated on the top in order to avoid an unrealistic extrapolation above the measured run up on the model. Elevations of the application force point have been obtained by determining barycenter time histories of the vertical spatial distributions.
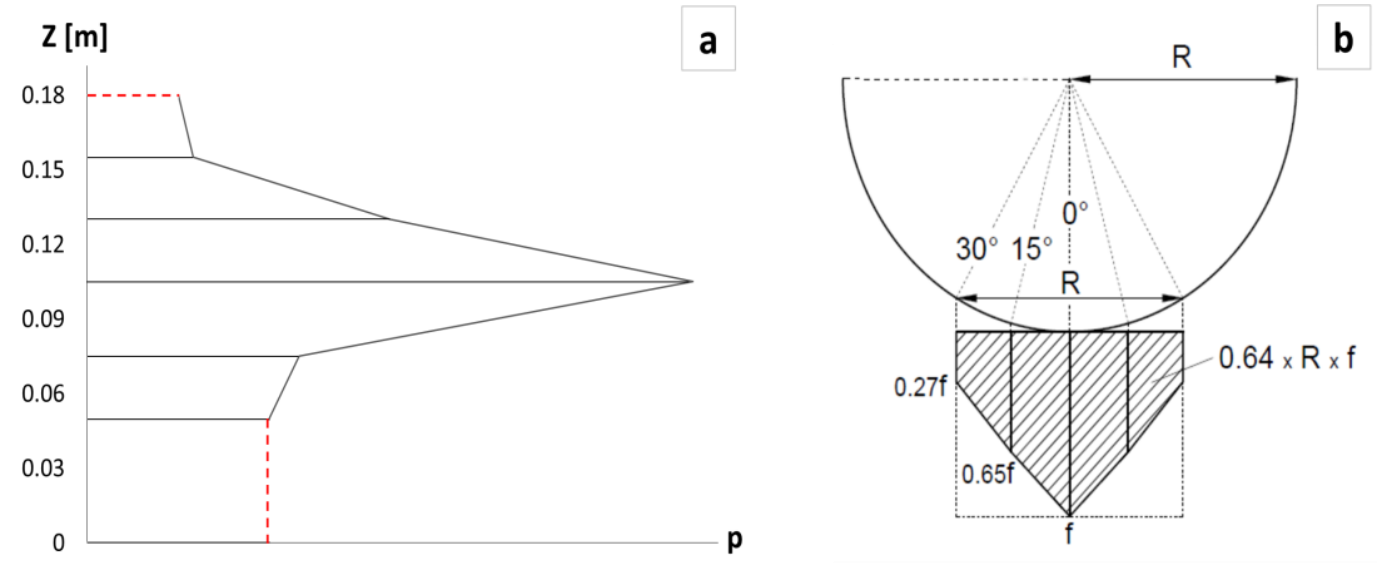

Figure 4. (a) Integration method to calculate the vertical spatial distribution and related force in line f; (b) azimuthal distribution for the estimation of the overall force $F$

\section{Azimuthal distribution and estimation of the overall force}

The spatial integration of the pressure measurements gives the force in line (f) with the central section of the cylindrical model (Fig. 4a). An estimation of the overall force (F) has been obtained 
according to the azimuthal distribution derived from pressure measures shown in Wienke and Oumeraci (2005). They measured pressures around a vertical cylinder and they found that the pressures at $\pm 15^{\circ}$ and $\pm 30^{\circ}$ were 0.65 and 0.27 times lower than the pressure in line with the wave direction (i.e. at $0^{\circ}$ ). As a consequence, their azimuthal integration results 0.64 times smaller with respect to a force line equally distributed along a horizontal extension equal to the radius of the cylinder (Fig. 4b). Note that the distance between $+30^{\circ}$ and $-30^{\circ}$ coincides with the radius of the cylinder $(\mathrm{R})$ and for the present analysis it was fixed equal to $0.10 \mathrm{~m}$ (i.e. equivalent to the radius of the cylindrical base).

\section{RESULTS AND DISCUSSION}

Classification and description of breaker types

The test program, previously described, generates non-breaking and breaking waves. The first three waves in each wave train were omitted from the analysis, as they had not reached the required amplitude; instead the subsequent 15-20 waves were analysed. The magnitude of wave pressures tends to be rather random from wave to wave of the same test, despite the repeatability of the breaking point. However, the nature of the load characteristics tends gradually to vary from test to test on the basis of the breaking distance $(x)$ with respect to the lighthouse model. In particular, the load impulsivity increases as the relative breaking distance decreases $\left(d=x / H_{b}\right)$.

Except for non-breaking/slightly breaking and spilling waves, which cause lower wave loadings, the load characteristics have been classified into four main breakers types on the basis of the relative breaking distance as follows:

- $\quad$ weak impact $\left(x / H_{b}=0.1-0.5\right)$;

- $\quad$ violent impact $\left(x / H_{b}=0.5-1.5\right)$;

- $\quad$ large air pocket $(x / H b=1.5-3.5)$;

- $\operatorname{broken}\left(x / H_{b}>3.5\right)$.

Fig. 5 shows video images of four examples that are used to describe the typical load characteristics of the four breaker types. The subsequent paragraphs provide data from these particular experiments.
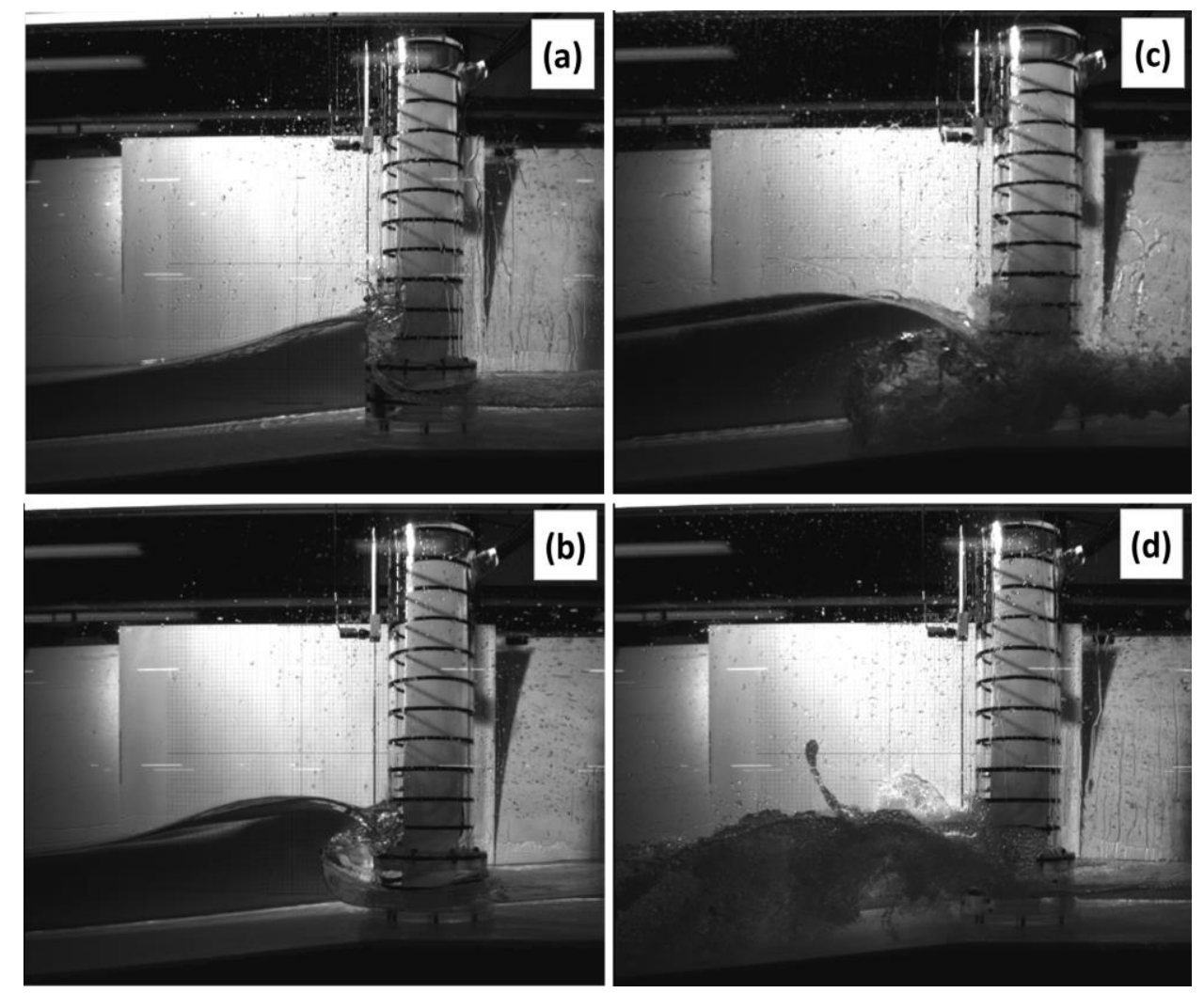

Figure 5. (a) weak impact $\left(H_{0}=0.11 \mathrm{~m}, \mathrm{~T}=1.4 \mathrm{~s}\right)$; (b) violent impact $\left(\mathrm{H}_{0}=0.13 \mathrm{~m}, \mathrm{~T}=1.8 \mathrm{~s}\right)$; (c) large air pocket $\left(H_{0}=0.17 \mathrm{~m}, \mathrm{~T}=2.2 \mathrm{~s}\right)$; (d) broken $\left(H_{0}=0.22 \mathrm{~m}, \mathrm{~T}=2.4 \mathrm{~s}\right)$. 


\section{Weak impact}

This is a small plunging impact that breaks approximately at the model with the wave front almost vertical (Fig. 5a). Impulsive pressure time histories are highly localised in space and they tend to occur in the proximity of transducer 3 (above SWL). Here, the impinging jet causes a rapid pressure spike, followed by the quasi-static component of the wave surface (Fig. 6a). Usually, the other pressure transducers (under and above the area hit by the small plunging jet) do not exhibit the occurrence of a pressure spike. The maximum measurements, related to the pressure transducers under SWL, occur first, followed by quasi-static loads measured above the impact area from the subsequent run up. Very often, the pressure records show high frequency oscillations at the location just below the occurrence of the impulsive peak. These oscillations, which occur later than the impulsive peak, suggest the presence of a small amount of air (transducer 4 in Fig. 6a).

The integrated force (F) exhibits a sharper peak highly localised in time (Fig. 6b). The instant of the maximum force is coincident with the instant of the maximum peak in the barycentre time history (dimensionless with respect to the water depth at the toe of the lighthouse, i.e. $h_{t}=0.095 \mathrm{~m}$ ) (Fig. 6c). At this instant, the spatial distribution tends to be a sharp triangle with the peak above SWL (Fig. 6d).
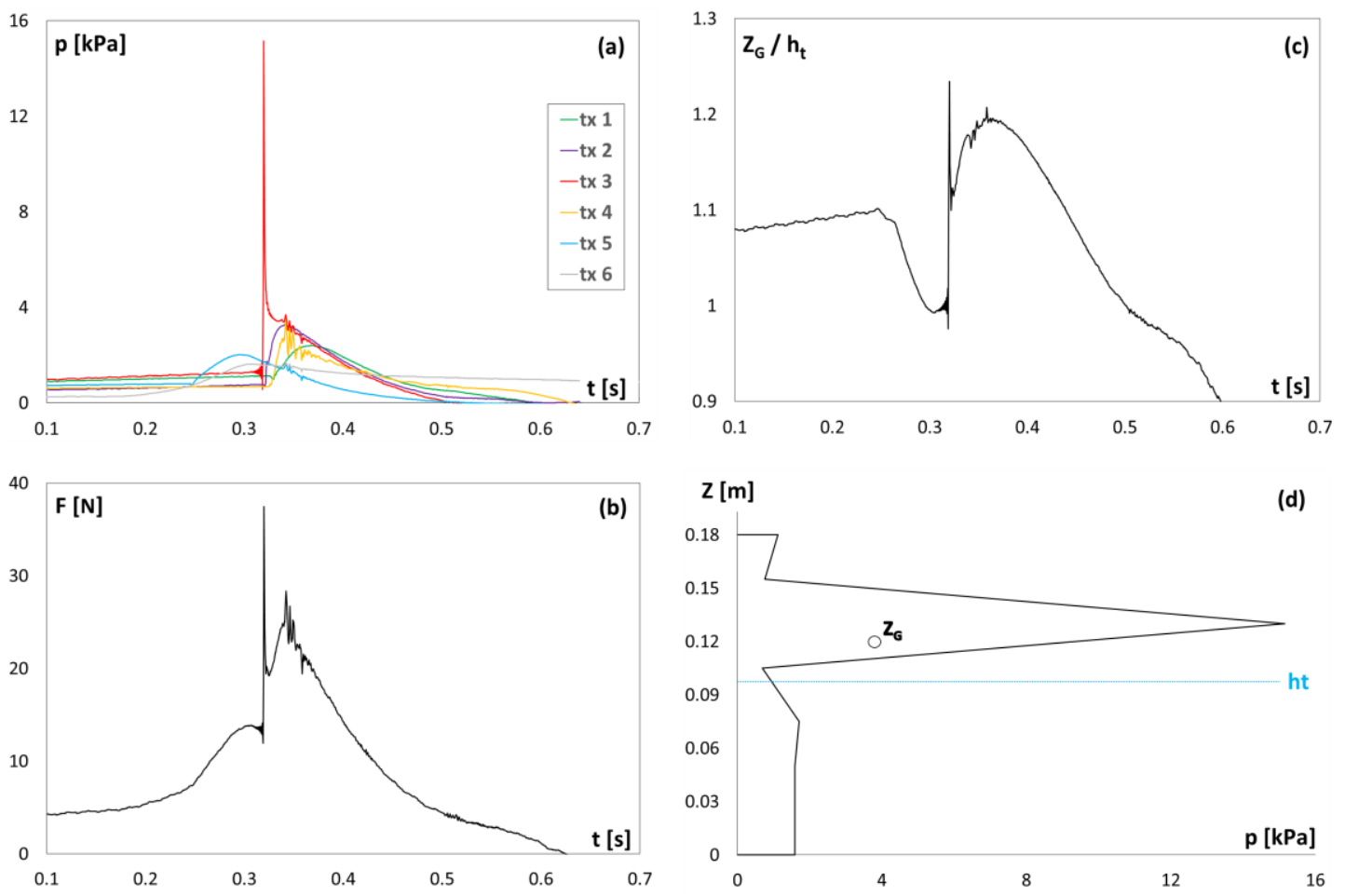

Figure 6. Weak impact $(\mathrm{Ho}=0.11 \mathrm{~m}, \mathrm{~T}=1.4 \mathrm{~s})$ : (a) pressure time histories; (b) overall force time history; (c) dimensionless barycentre time history; (d) vertical spatial distribution at the maximum force peak.

\section{Violent impact}

With respect to the previous breaker, this is a larger plunging impact that breaks relatively close to the model (Fig. 5b). Impulsive pressures tend to occur over all the pressure transducers, also for those under the SWL (Fig. 7a). All the pressure time histories tend to have a well-defined triangular shape and, frequently, extreme spikes are visible on the top of the triangular peaks (Fig. 7a). The maximum pressure peak, highly localised in the time, occurs randomly between the four pressure transducers above SWL (i.e. $\mathrm{tx} 1, \mathrm{tx} 2$, tx3 and tx4) depending on the direction of the forward jet. High frequency oscillations after maximum peaks indicate the presence of air, as confirmed by video images (Fig. 5b).

The integrated force (F) results in a triangle with a sharp spike on the top (Fig. 7b). Often, the first pressure spike, which occurs for the highest pressure transducers (i.e. tx1 and tx2), is so localised (in both time and space) that it loses its effects when the pressures are integrated over the whole interface of the lighthouse model (Fig. 7b). As a consequence, the maximum peaks in the barycentre $\left(\mathrm{Z}_{\mathrm{G}} / h_{t}\right)$ and force time $(\mathrm{F})$ histories do not occur at the same instant (Fig. 7b-c). However, spatial distributions, at 
the instant of the maximum peak force $(\mathrm{F})$, tend to be triangular; but the shape tends to be wider than that of the weak impact and with the peak just slightly above the SWL (Fig. 7d).
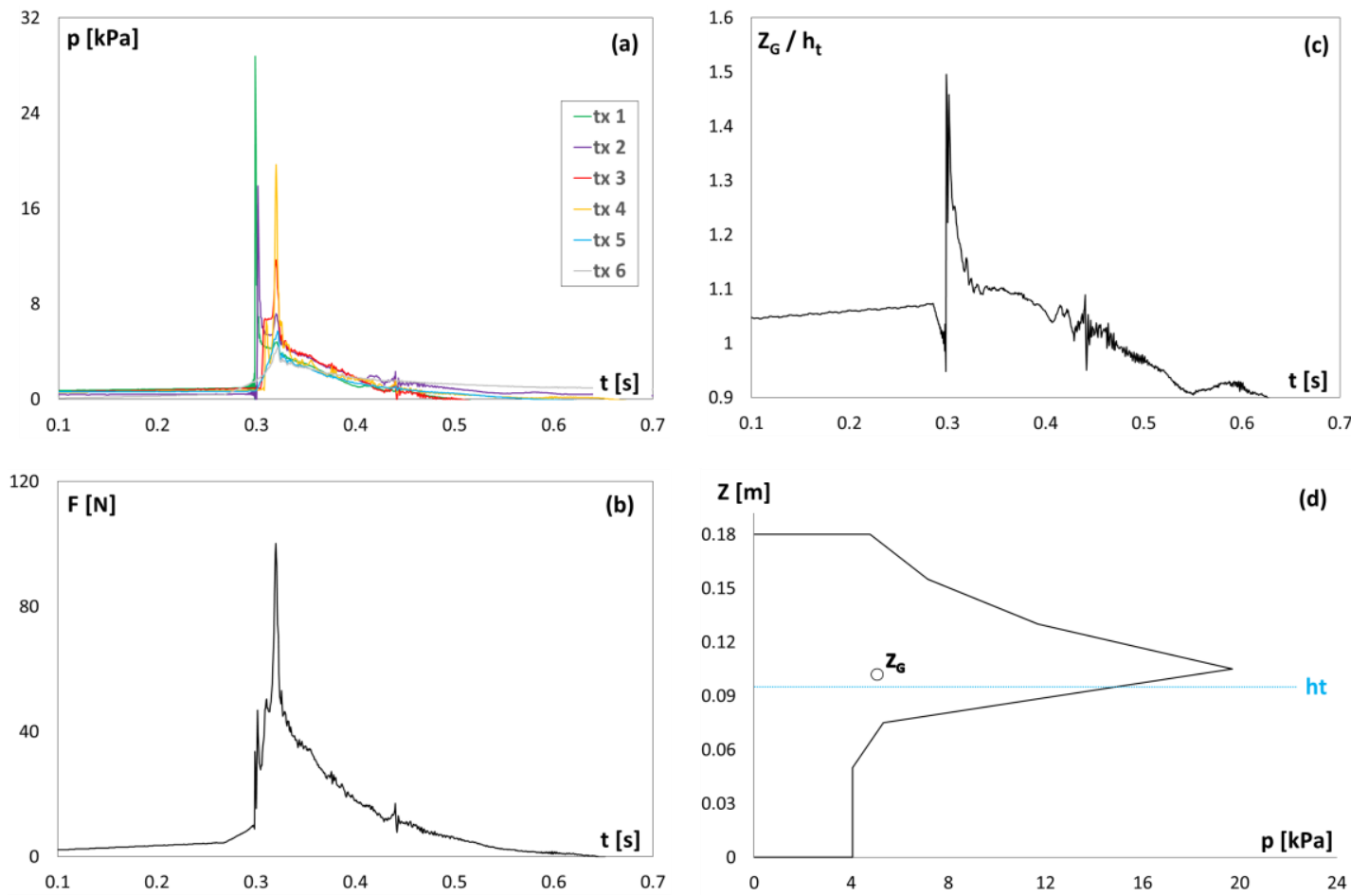

Figure 7. Violent impact $(\mathrm{Ho}=0.13 \mathrm{~m}, \mathrm{~T}=1.8 \mathrm{~s})$ : (a) pressure time histories; (b) overall force time history; (c) dimensionless barycentre time history; (d) vertical spatial distribution at the maximum force peak.
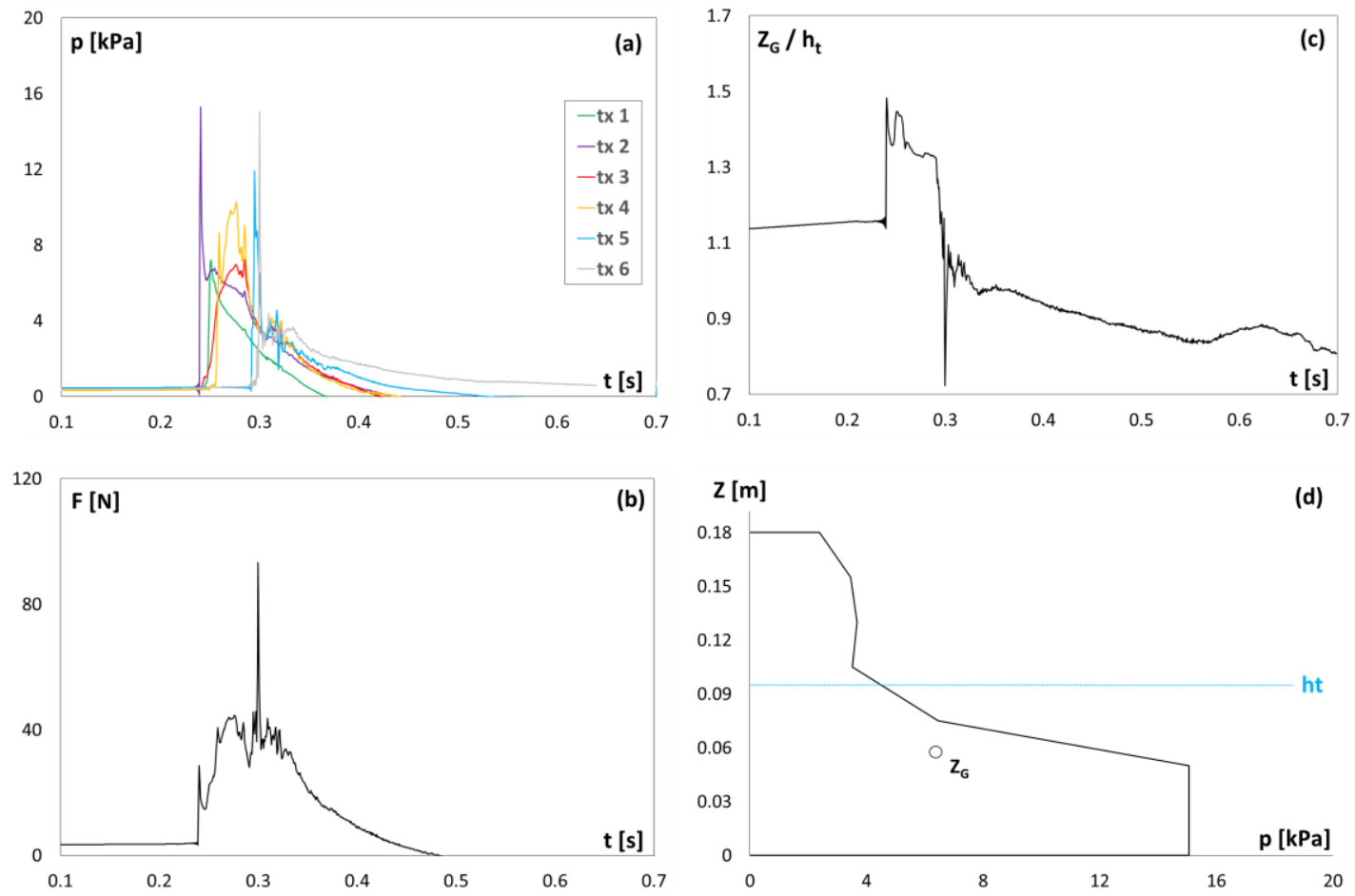

Figure 8. Large air pocket $(\mathrm{Ho}=0.17 \mathrm{~m}, \mathrm{~T}=2.2 \mathrm{~s})$ : (a) pressure time histories; (b) overall force time history; (c) dimensionless barycentre time history; (d) vertical spatial distribution at the maximum force peak. 


\section{Large air pocket}

This is a large plunging wave that breaks farther from the lighthouse model due to the limited water depth condition. The wave crest, which overturns and hits the model as it falls down, can entrap a large air pocket (Fig. 5c). Maximum run up, approximately 4 times the water depth $h_{t}$, occurred for this breaker type. However, this value is lower with respect to the maximum run up observed in the 3D situation of the field during the UK winter storms of 2013/2014 (Raby et al. 2015).

This breaker exhibits two distinct temporal phases. The first phase is caused by the falling-down jet, which generates impulsive pressures above the SWL; the second phase is caused by the incoming wave that generates impulsive pressures under the SWL (Fig. 8a). Although the maximum pressure peak can occur in both the phases, it tends to be smaller and wider when compared to those recorded for violent impact type. In addition, the effects of the entrapped air generate irregular oscillations, recorded under SWL, after the secondary peaks (Fig. 8a).

As consequence of the distinct phases, the force time history $(F)$ shows several peaks and its shape is less triangular than that of the violent impact type (Fig. 8b).

The barycentre time history $\left(\mathrm{Z}_{\mathrm{G}} / h_{t}\right)$ shows the line of action moves from above to under SWL (Fig. $8 \mathrm{c})$. Despite the repeatability of the barycentre time histories, two different spatial distributions can be associated with this breaker depending on whether the maximum peak force occurs in the first or in the second phase. When the maximum force peak is related to the falling-down jet, the spatial distribution has a triangular shape similar to that of the violent impact type (Fig. 7d). Alternatively, when the maximum force peak is caused by the incoming wave, the spatial distribution is characterised by a wide area under the SWL (Fig. 8d).

\section{Broken}

The wave crest strikes the water and the cylinder is subsequently hit by a turbulent mass of water with high residual velocities (Fig. 5d). This breaker tends to cause lower run up, even if these wave impacts tend to persist for longer durations.
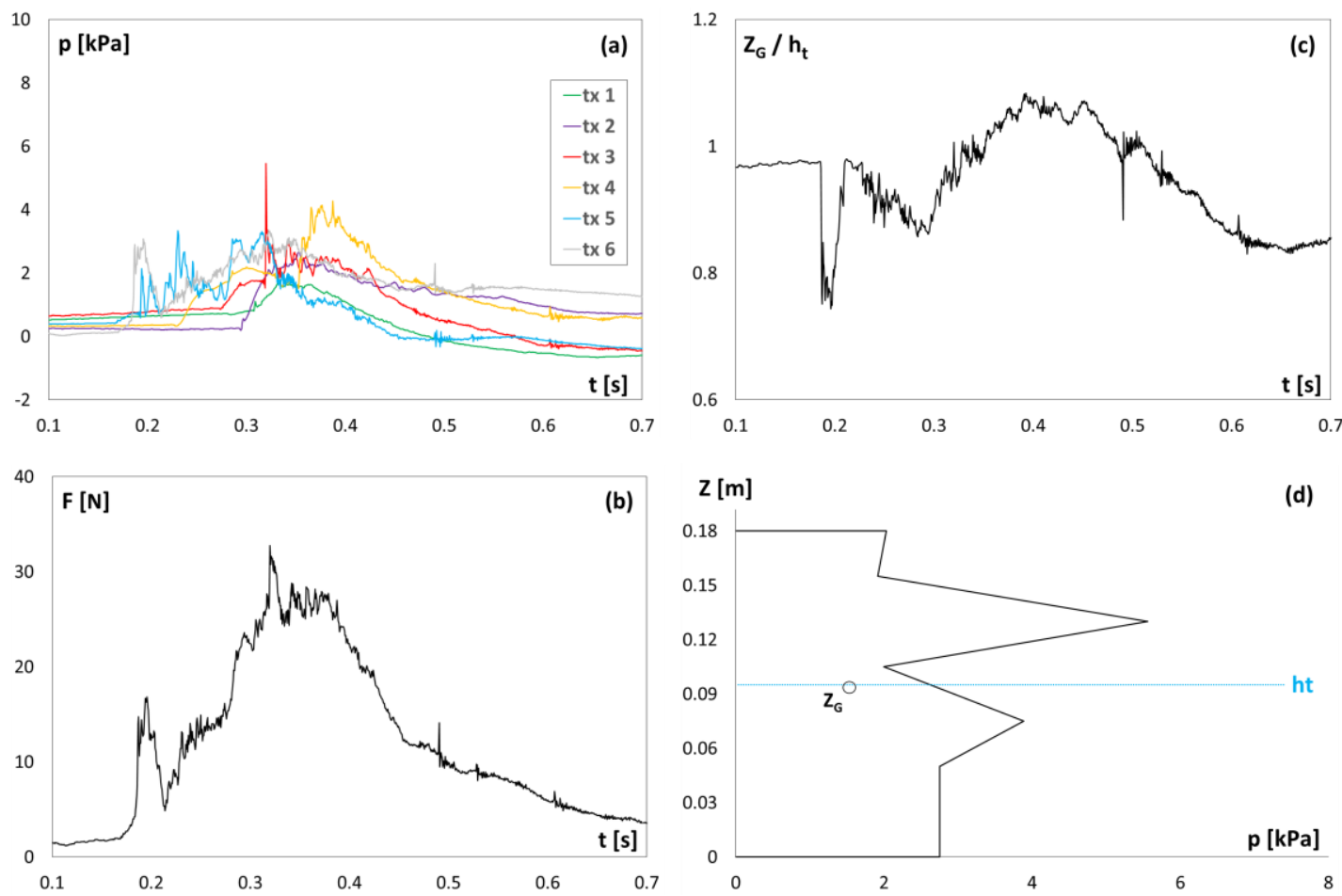

Figure 9. Broken $(\mathrm{Ho}=0.22 \mathrm{~m}, \mathrm{~T}=2.4 \mathrm{~s})$ : (a) pressure time histories; (b) overall force time history; (c) dimensionless barycentre time history; (d) vertical spatial distribution at the maximum force peak.

All the pressure transducers tend to show a highly variable signal characterised by random peaks due to the impact of the air-water mixture (spray) and secondary small jets (Fig. 9a). The pressure 
measurements are not in phase with each other and the pressure event moves gradually from tx6 (lower transducer) to tx1 (upper transducer) due to the turbulent bore that runs up the model (Fig. 9a).

The integrated force (F) shows a quasi-static noisy signal (Fig. 9b); usually, two peaks can be observed because pressures are not simultaneous.

The barycentre of the spatial distributions moves from under to above SWL (Fig. 9c). Due to the fact that pressure magnitudes from $\mathrm{tx} 3, \mathrm{t} \times 4$ and $\mathrm{tx} 5$ tend to be similar, the maximum spatial distributions can occur slightly under or above SWL. Although they tend to be characterised by a more uniform distribution over the whole impact extent, the shape is completely random (Fig. 9d).

\section{Load characteristics and wave parameters}

The magnitude of wave pressures tends to be rather random from wave to wave for the same test, despite the repeatability of the breaking point. Fig. 10 shows dimensional and dimensionless pressure peaks against Iribarren number and momentum flux. The peaks are the maximum values recorded for each test by each pressure transducer (six in total). The dimensional values are in $\mathrm{kPa}$, while the dimensionless values (usually used as an indicator of the impulsivity) are obtained by dividing the pressure by the specific weight of the water $\gamma$ and the offshore wave height $H_{o}$ i.e. measured before the wave transformation that occurs on the 1:20 slope.
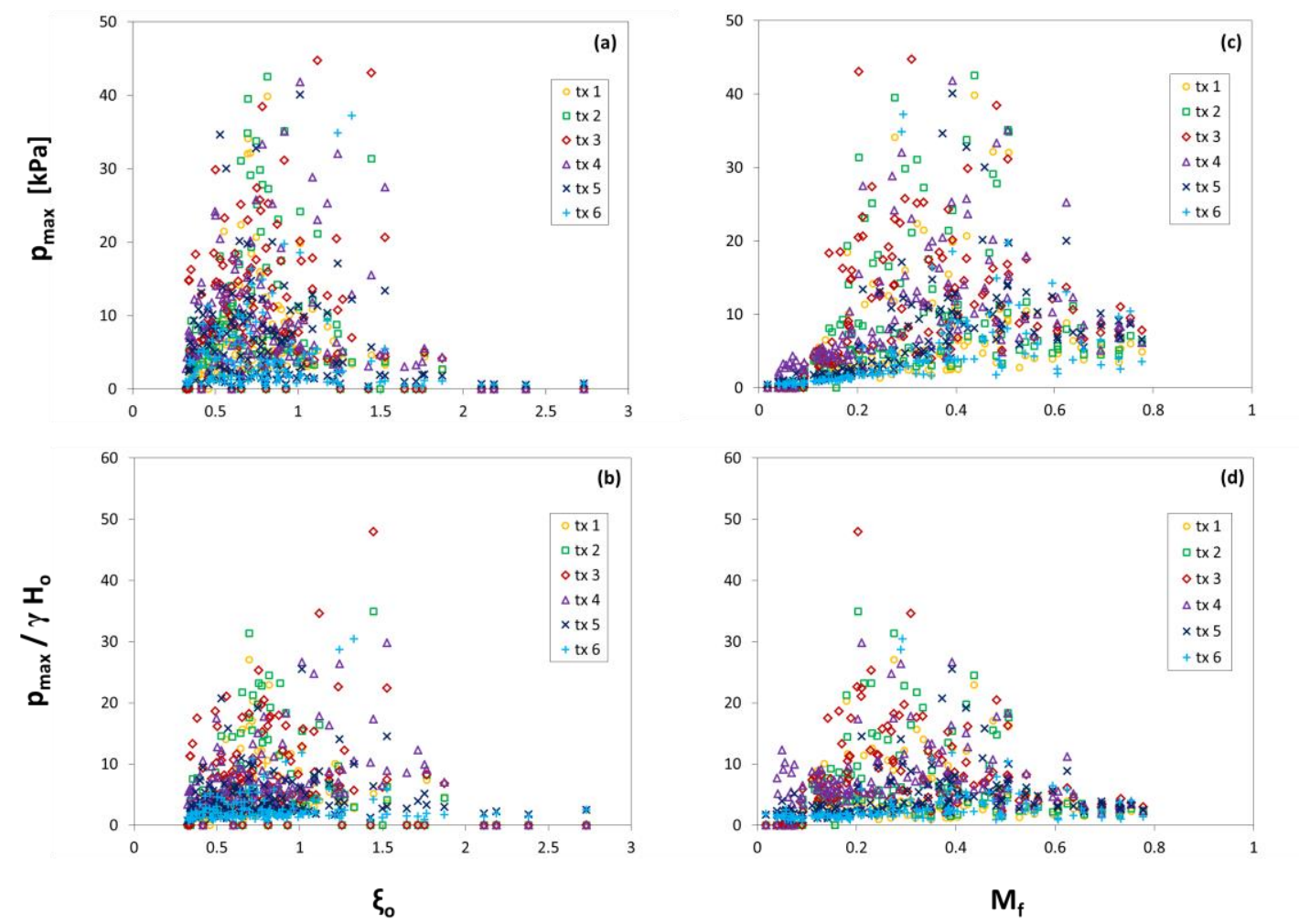

Figure 10. Dimensional (upper) and dimensionless (bottom) pressures vs $\xi_{0}$ (left) and $M_{f}$ (right)

As may be observed from Fig. 10a-b, pressure peaks are quite random when plotted against $\xi_{0}$. Also, similar maximum values (dimensional and dimensionless) can occur over a large range $\left(0.4<\xi_{0}<1.5\right)$. However, the pressures are much smaller when $\xi_{0}>1.5$. This is due to the fact that plunging waves can occur if $\xi_{0}<1.5$, instead only non-breaking/slightly breaking wave occur when $\xi_{0}>1.5$. When $1.0<\xi_{0}<1.5$, dimensionless values tend to show a larger scatter because they are characterised by stronger wave transformation. When plotted against $M_{\mathrm{f}}$, most of the highest dimensional pressure peaks occur over the range 0.2-0.6 (Fig. 10c). This is given by the fact that nonbreaking/slightly breaking waves occur only if $M_{\mathrm{f}}<0.2$, while only broken waves occur when $M_{\mathrm{f}}>0.6$. Except for the lower values in the first part $\left(M_{\mathrm{f}}<0.2\right)$, where waves are non-breaking/slightly breaking, the dimensionless pressure shows a tendency to decrease with the increase in the momentum flux. 
Fig. 11 shows dimensional and dimensionless maximum force peaks against Iribarren number and momentum flux. The dimensionless values are obtained by dividing the force line (f) by the specific weight of the water $\gamma$, the offshore wave height $H_{o}$ and the water depth at the toe of the cylinder $h_{t}$. As for the dimensional and dimensionless pressures, most of the highest force peaks tend to occur for $\xi_{0}<1.5$ and $0.2<M_{\mathrm{f}}<0.6$ (Fig. 11).
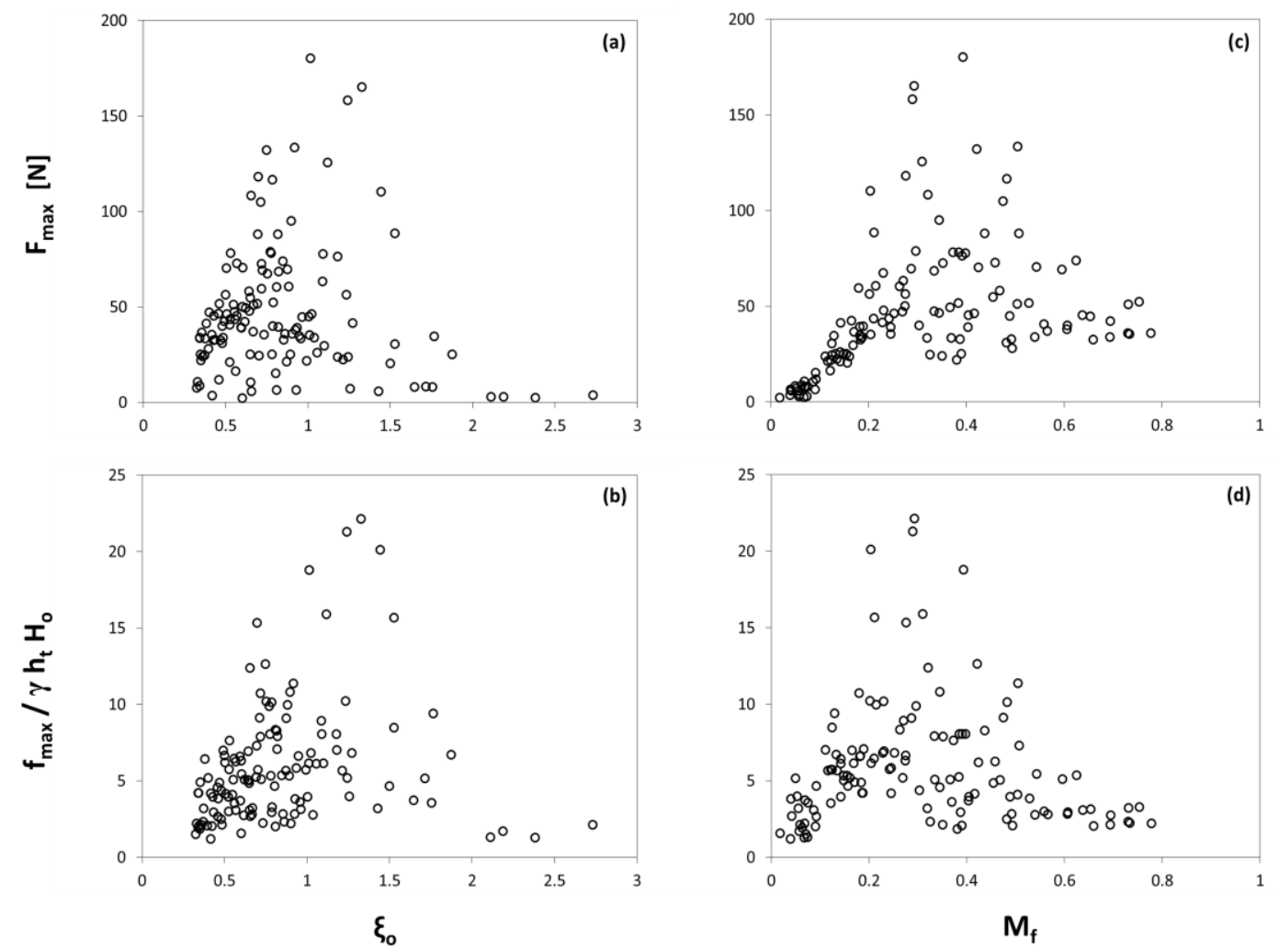

Figure 11. Dimensional (upper) and dimensionless (bottom) force vs $\xi_{0}$ (left) and $M_{f}$ (right)
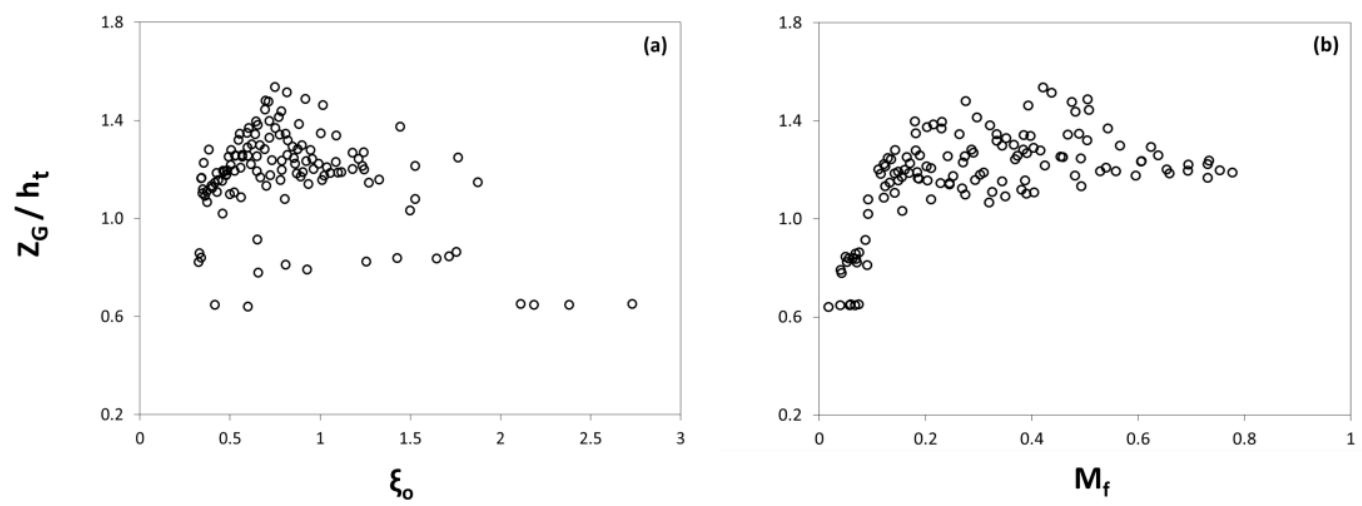

Figure 12. Maximum dimensionless barycenter peaks vs $\xi_{0}$ (left) and $M_{f}$ (right)

As may be observed by comparing Fig. 11c and 11d, momentum flux below 0.2 show a scatter moving from dimensional to dimensionless value. This portion of data includes slightly-breaking waves, which are characterised by small offshore wave heights that become steeper in the proximity of the model. As a result, they cause small impulsive load peaks with respect to the offshore wave heights. However, the dimensional forces are rather small because these waves are so small that the two upper transducers did not record the pressure event. Moreover, events with $M_{\mathrm{f}}>0.6$ generate larger forces 
(dimensional values) with respect to those with $M_{\mathrm{f}}<0.2$, even if the latest exhibit stronger impulsivity (i.e. larger dimensionless values).

In the previous section spatial distributions that occur at the instant of the maximum force were described. Figure 12 shows the maximum peaks of the barycentre time history. These peaks are plotted against the Iribarren number and momentum flux. As may be observed, the Iribarren number does not show a clear tendency (Fig.12a). Instead, when plotted against the momentum flux, the lowest barycentre peaks occur for $M_{\mathrm{f}}<0.2$, then the highest values (approximately 1.5) occur over the range 0.2-0.6 and they tend to 1.2 when $M_{\mathrm{f}}>0.6$ (Fig.12b).

\section{Occurrence of breaker types on the $\xi_{0}-M_{f}$ plane}

As may be observed from Fig. 13, the breaker types tend to cover certain areas of the plane $\xi_{0}-M_{\mathrm{f}}$, where data are plotted according to the measured offshore wave height $H_{o}$. In particular, the breaker types tend to gradually vary with the momentum flux, moving from non-breaking to broken wave. As a consequence, the relative breaking distance tends to increase with the increasing of $M_{\mathrm{f}}$. Only small waves (weak impact, slightly breaking and non-breaking) occur when $\xi_{0}>1.5$. Spilling breakers tend to occur according to wave steepness limit (curve a). Similarly, waves break for excess of wave height in the proximity of the depth section $h^{*}=0.24 \mathrm{~m}$, in agreement with the wave height limit (curve b).

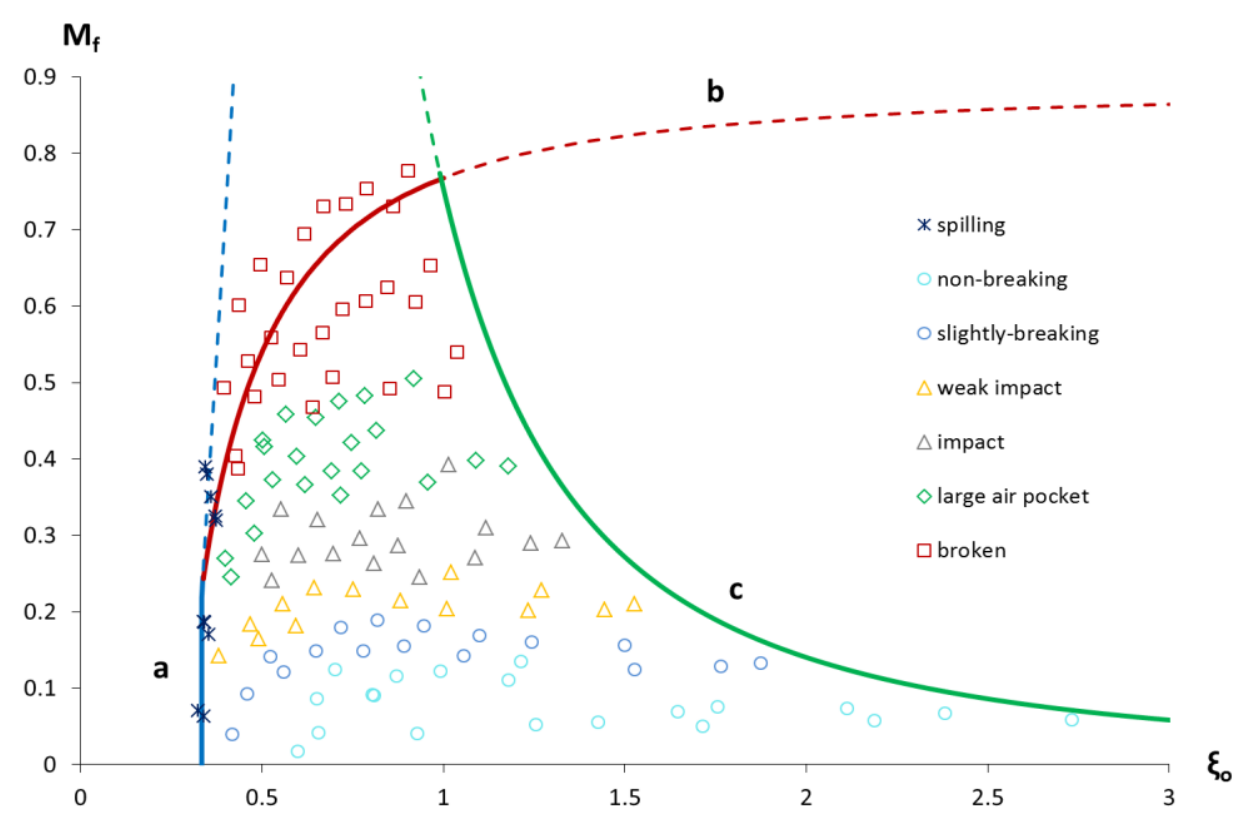

Figure 13. Breaker types occurrence on the dimensionless plane $\xi_{0}-M_{f}$

Fig. 14 shows histograms of the maximum peaks (pressure and overall force) recorded for the four breaker types previously described. The peaks are shown for both dimensional and dimensionless values. As may be observed, the dimensionless pressures decrease from weak impact to broken. Consequently, the impulsivity of the pressure signals tends to decrease with the increasing of the relative breaking distance. In contrast, weak impact, violent impact and large air pocket are able to generate similar dimensional pressures (Fig. 14). This means that smaller waves (weak impact), characterised by smaller masses, can generate pressures similar to those generated by larger wave heights. Thus, due to the fact that pressure transducers provide spatially localised measurements, the pressures may be more affected by the acceleration of the water than by the amount of the water mass.

In contrast with pressure, dimensional forces exhibit larger scatter among the four breaker types, and maximum values (both dimensional and dimensionless) are given by violent impact type (Fig. 14). This result is caused by the fact that a couple of vertical spikes tend to be almost simultaneous over two pressure transducers for the violent impact type. As a consequence, the integrated force (f) tends to show a strong vertical spike highly localised in time. Although the weak impact types arises from a plunging wave that breaks at the structure with the wave front almost vertical, it causes lower forces when compared to breaker characterised by larger breaking distances. This is explained by the fact that 
the lighthouse model is in depth limited conditions and only small plunging waves are able to break at the structure. Thus, even if larger plunging waves break farther from the lighthouse, they are characterised by larger wave heights and periods that generate larger forces.

Dimensional values
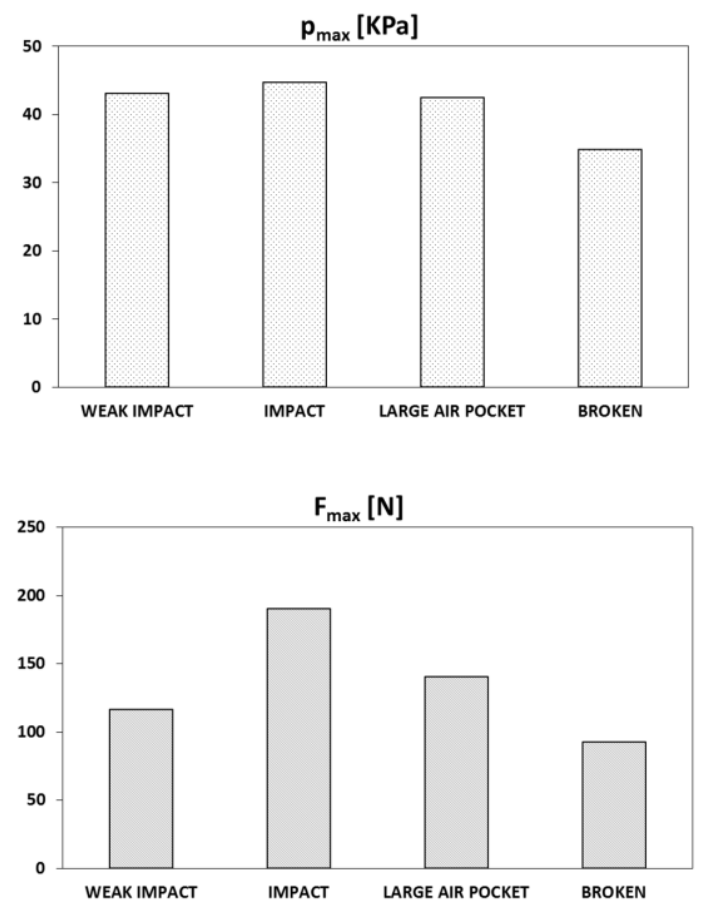

Dimensionless values

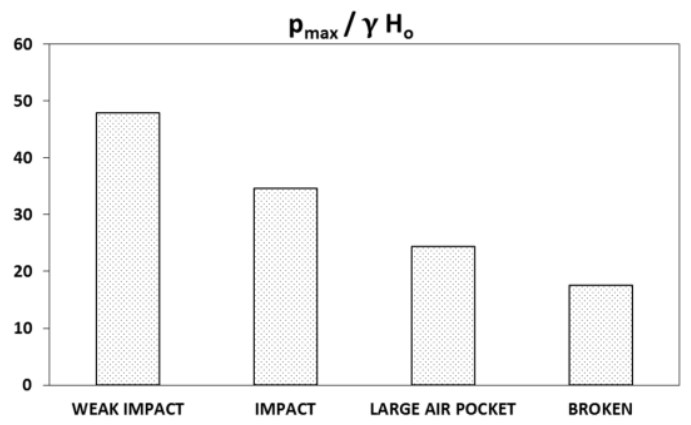

$f_{\max } / \gamma h_{t} H_{0}$

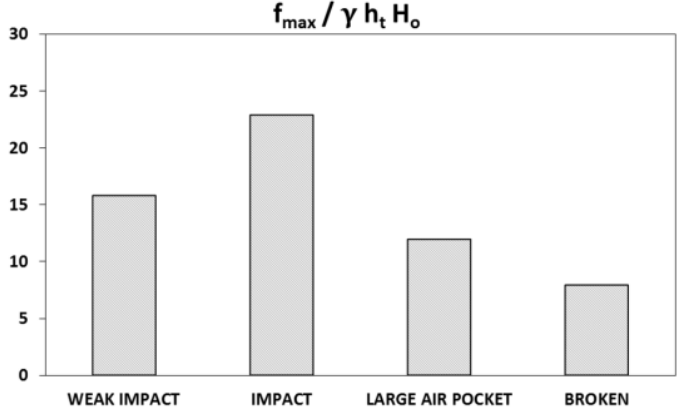

Figure 14. Histograms of the maximum load peaks recorded for the four breaker types. At the top are pressures and on the bottom forces; at the left dimensional values and on the right dimensionless values.

\section{CONCLUSIONS}

Four main groups of load characteristics have been identified and classified in four breaker types on the basis of the relative breaking distance. Although the repeatability of the breaking point for the same wave regular test is consistent, the magnitude of pressures is rather random wave by wave. However, the pressure impulsivity increases as the relative breaking distance decreases.

Vertical spatial distributions and barycentre time histories of the force have been also investigated. Weak impact and impact are characterised by triangular vertical distributions with the barycentre above SWL. The barycentre time history shows that the line of action moves from above to under SWL for large air pocket. Thus, depending on the instant of the maximum force peak, two different spatial distributions can occur: triangular, with the barycentre above SWL, or trapezoidal, with the barycentre under SWL. For broken waves the barycentre moves from under to above SWL, but the shape of the spatial distribution is random and the barycentre can occur slightly under or slightly above SWL.

Due to the limited depth condition at the toe of the lighthouse, only small plunging waves are able to break at the structure. As a consequence, larger overall forces (from integrated pressures) are caused by larger waves, even if they break farther from the lighthouse.

In addition, the occurrence of breaker types has been investigated in a sort of dimensionless breaking map given by the combination of the Iribarren number and momentum flux of Hughes.

Within this experimental campaign, overall force measurements were also obtained by using load cells and results will be presented in future works.

\section{ACKNOWLEDGMENTS}

The authors would like to acknowledge Alastair Reynolds and Peter Arber for the assistance provided during the laboratory test and the School of Marine Science and Engineering who funded the $\mathrm{PhD}$ project of $\mathrm{D}$. Banfi. The authors are also grateful to Professor G. Bullock for his stimulating thoughts and for the valuable suggestions provided during the aforementioned $\mathrm{PhD}$ project. 


\section{APPENDIX}

Waves are affected by transformations when they propagate from deep $(h / L>0.5)$ to shallow waters $(h / L<0.05)$. The decrease of the depth implies the decrease of the wave length and the variation of the offshore wave height $H_{o}$ for shoaling (Fig. A-1).

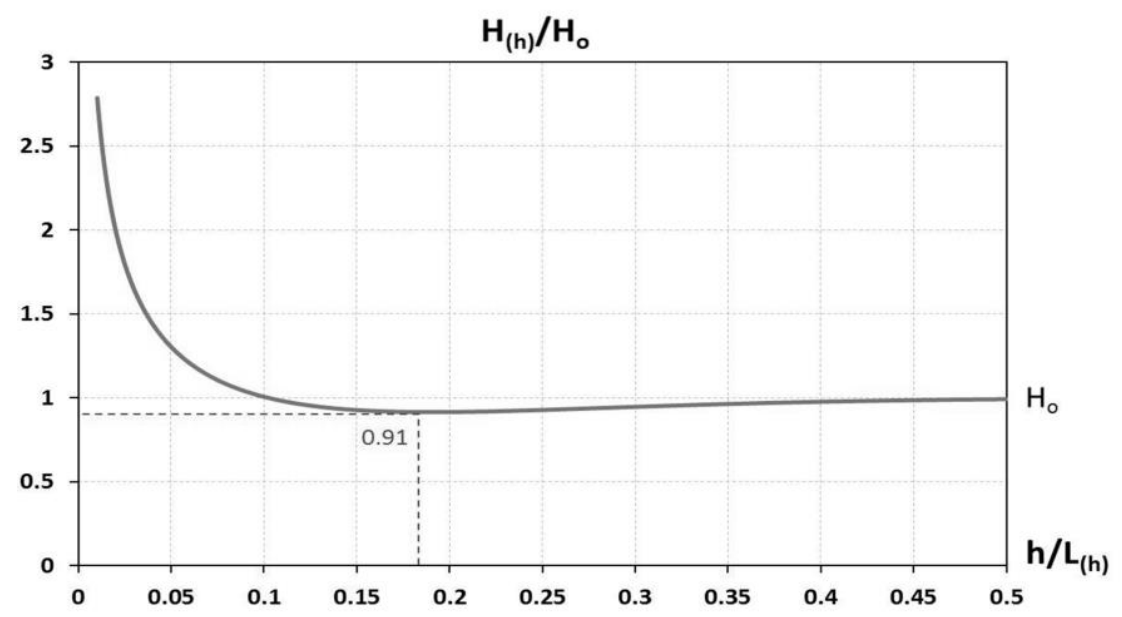

Figure A-1. Shoaling curve: wave height $H_{(h)}$ variation that occurs during the wave propagation.

The local wave length $L_{(h)}$ at the generic water depth $h$ is calculated according to the linear dispersion relationship (Eq. A-1).

$$
L_{(h)}=L_{o} \tanh k h=\frac{g T^{2}}{2 \pi} \tanh k h
$$

In the surf zone the wave height can reach a limiting value. Above this value, the wave breaks for excess of wave height with respect to the water depth. The breaking limit is calculated according to the relative wave height $H_{b} / h_{b}$ and it depends on both slope $(\alpha)$ and offshore wave steepness (H/L). Figure A-2 shows the breaking limits proposed by Weggel (1972) for regular waves and Eq. A-2 the breaking limit related to the slope 1:20.

$$
\frac{H_{b}}{h_{b}}=1.13-26.5 \frac{H_{b}}{g T^{2}}
$$

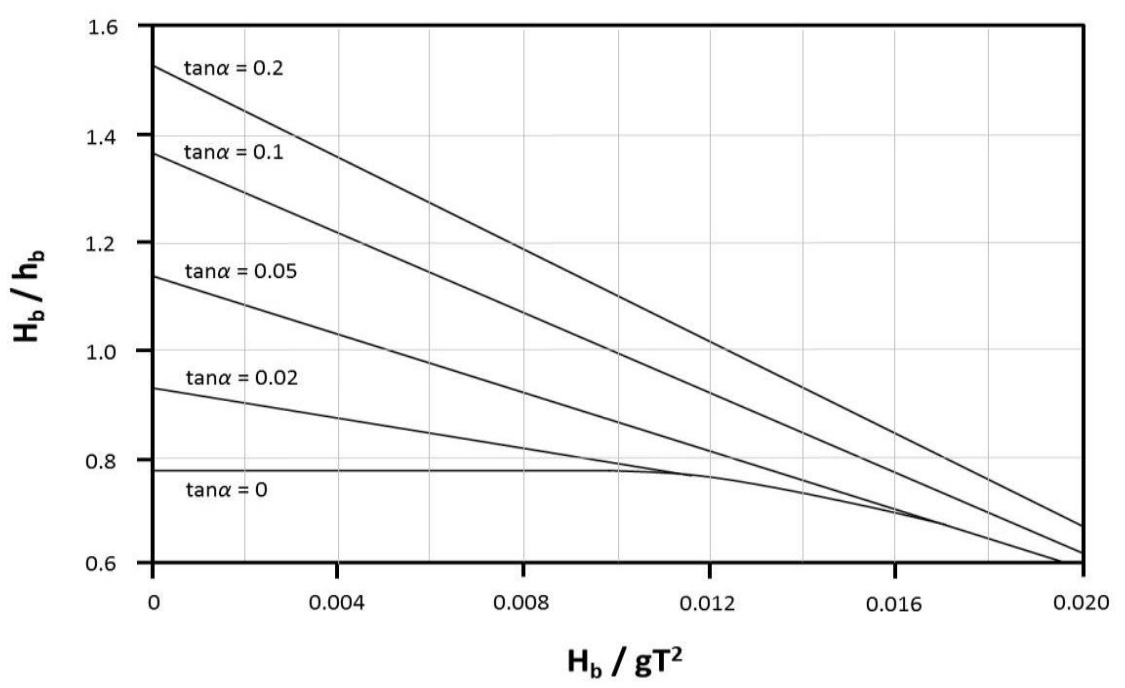

Figure A-2. Breaker depth index (for regular wave) as a function of wave steepness $\mathrm{H}_{\mathbf{b}} / \mathrm{gT}^{2}$ (Weggel 1972) 


\section{REFERENCES}

Bagnold, M.R.A. 1939. Interim report on wave-pressure research. Proc. Inst. Civ. Engrs, 12, 201-226.

Battjes, J.A. 1974. Surf similarity. Proceedings $14^{\text {th }}$ Coastal Engineering Conference. ASCE, New York, N.Y., 466-480.

Blenkinsopp, C. E., and J. R. Chaplin. 2011. Void fraction measurements and scale effects in breaking waves in fresh water and sea water. Coastal Engineering, 58(5), 417-428.

Bredmose, H., D.H. Peregrine, and G.N Bullock. 2009. Violent breaking wave impacts. Part 2: modelling the effect of air. Journal of Fluid Mechanics, 641, 389-430.

Bredmose, H., G.N. Bullock, and A.J. Hogg. 2015. Violent breaking wave impacts. Part 3. Effects of scale and aeration. Journal of Fluid Mechanics, 765, 82-113.

Bullock, G.N., A.R. Crawford, P.J. Hewson, M.J.A. Walkden, and P.A.D. Bird. 2001. The influence of air and scale on wave impact pressures. Coastal Engineering, 42(4), 291-312.

Bullock, G., C. Obhrai, G. Müller, G.Wolters, H. Peregrine, and H. Bredmose. 2003. Field and laboratory measurements of wave impacts. In Proc. Coastal Structures (pp. 343-355).

Bullock, G.N., C. Obhrai, D.H. Peregrine, and H. Bredmose. 2007. Violent breaking wave impacts. Part 1: Results from large-scale regular wave tests on vertical and sloping walls. Coastal Engineering, 54(8), 602-617.

Cuomo, G., W. Allsop, and S. Takahashi. 2010. Scaling wave impact pressures on vertical walls. Coastal Engineering, 57(6), 604-609.

Cuomo, G., R. Piscopia, and W. Allsop. 2011. Evaluation of wave impact loads on caisson breakwaters based on joint probability of impact maxima and rise times. Coastal Engineering, 58(1), 9-27.

Galvin, C. J. 1968. Breaker type classification on three laboratory beaches. Journal of geophysical research, 73(12), 3651-3659.

Goda, Y. 1974. New wave pressure formulae for composite breakwaters. Proc. 14th International Conference on Coastal Engineering, pp 1702-1720, Copenhagen, publn. ASCE, New York.

Hattori, M., A. Arami, and T. Yui. 1994. Wave impact pressure on vertical walls under breaking waves of various types. Coastal Engineering, 22(1), 79-114.

Hughes, S. A. 2005. Wave momentum flux parameter: a descriptor for nearshore waves. Coastal Engineering, 51(11), 1067-1084.

Hull, P., and G. Müller. 2002. An investigation of breaker heights, shapes and pressures. Ocean Engineering, 29(1), 59-79.

Kyte, A., and A. Tørum. 1996. Wave forces on vertical cylinders upon shoals. Coastal engineering, 27(3), 263-286.

Muttray, M., H. Oumeraci, K. Shimosako, and S. Takahashi. (1998). Hydraulic performance of a high mound composite breakwater. Coastal Engineering Proceedings, 1(26).

Oumeraci, H., P. Klammer, H.W. Partenscky. 1993. Classification of breaking wave impact loads on vertical structures. ASCE, J. Waterway, Port, Coastal and Ocean Eng., 119(4), 381-397.

Raby, A., G. Bullock, D. Banfi, Y. Rafiq, and F. Cali. 2015. Wave loading on rock lighthouses. In Proceedings of the Institution of Civil Engineers-Maritime Engineering, Vol. 169, No. 1, pp. 1528. Thomas Telford Ltd.

Trinh, Q., A. Raby, D. Banfi, M. Corrado, B. Chiaia, Y. Rafiq, and F. Cali. 2016. Modelling the Eddystone Lighthouse response to wave loading. Engineering Structures, 125, 566-578.

Weggel, J. R. 1972. Maximum breaker height for design. Coastal Engineering Proceedings, 1(13).

Wienke, J., and H. Oumeraci. 2005. Breaking wave impact force on a vertical and inclined slender pile - theoretical and large-scale model investigations. Coastal Engineering, 52(5), 435-462. 